\title{
COMPONENTES DE PAISAGEM: O QUE TEM MAIOR EFEITO SOBRE A COMUNIDADE DE SCARABAEINAE (COLEOPTERA) EM FRAGMENTOS DE MATA ATLÂNTICA? \\ Gesica Regina Gomes da Silva ${ }^{1}$; Priscila Paixão Lopes ${ }^{2}$
}

1. Bolsista PROBIC/UEFS, Graduando em Ciências Biológicas, Universidade Estadual de Feira de Santana, e-mail: gesicaregina@gmail.com

2. Orientadora, Departamento de Ciências Biológicas, Universidade Estadual de Feira de Santana, e-mail: pplc29@gmail.com

PALAVRAS-CHAVE: Scarabaeidae; paisagem; fragmentos florestais.

\section{INTRODUÇÃO}

Os besouros Scarabaeidae são popularmente chamados de rola-bostas. São conhecidas aproximadamente 7.000 espécies de Scarabaeidae em todo o mundo (SCHOOLMEESTERS et al., 2010) com maior concentração em florestas e savanas tropicais (HANSKI \& CAMBEFORT, 1991). Os Scarabaeinae não sofrem diretamente a influência da composição e estrutura da vegetação, porem são influenciados indiretamente por sua estrutura, uma vez que a vegetação determina a composição, abundância e estrutura da comunidade de vertebrados (principalmente mamíferos), que constituem a principal fonte de recursos (fezes e carcaças), além de determinar a condição abiótica do ambiente.

Segundo MacArthur \& Wilson (1967), a riqueza das comunidades consiste num balanço entre o nível de sobrevivência das populações das várias espécies (associado à área) e a chance de imigrantes recomporem as populações ou novas espécies chegarem (associado ao isolamento). Ambientes muito isolados, ou cercados por vegetações estruturalmente muito distintas dos fragmentos florestais (matriz muito heterogênea, METZGER, 2001), implicam em ampliação do isolamento, já que os besouros não conseguiriam se movimentar por esta matriz. As alterações de paisagem, e majoritariamente florestal para uma matriz mais aberta, podem afetar a abundância e a distribuição da biodiversidade em áreas, assim como a diversidade e estrutura da comunidade de Scarabaeidae em fragmentos florestais de Mata Atlântica, deste modo determinar se e como aspectos estruturais internos a cada fragmento e sua inserção na paisagem afetam a composição e estrutura da comunidade de besouros rola bosta (Coleoptera, Scarabaeidae, Scarabaeinae) sendo estas algumas determinantes para diversidade em fragmentos florestais.

\section{MATERIAL E MÉTODOS}

Foram escolhidos fragmentos dentro da APA do Pratigi, no litoral sul da Bahia (1353'52.3”S, 039²7'29.7” W), entre os municípios de Igrapiúna, Ibirapitanga, Ituberá, Nilo Peçanha e Piraí do Norte uma área de proteção ambiental com uma área total de 85.689 ha. É constituída de uma faixa territorial de grande interesse por apresentar remanescentes de Floresta Atlântica que abrangem 36,68\% de sua área (OCT, 2015). Nos seis fragmentos escolhidos, de tamanhos variados, foram realizadas amostragens da comunidade de Scarabaeidae e medições estruturais de vegetação. A coleta de besouros foi realizada em uma grade de nove pontos distantes no mínimo $50 \mathrm{~m}$ um do outro, e com a mesma distância mínima da borda do fragmento. Em cada ponto foram montadas dois pitfalls (baldes de $15 \mathrm{~cm}$ x $10 \mathrm{~cm}$ de altura, enterrados no solo até a abertura do balde), iscados com carcaça (baço bovino) e com fezes humanas. Dentro colocou-se uma solução de detergente a $2 \%$ e sal para matar e fixar os insetos. As armadilhas permaneceram no campo por 48 horas e depois os insetos foram recolhidos, fixados em álcool $70 \%$, e levados ao laboratório para triagem, montagem e 
identificação. Para os dados de paisagem utilizamos imagens digitais, fotografias verticais com lente olho de peixe (8mm - hemisférica), a $50 \mathrm{~cm}$ do solo e para analise das mesmas utilizou-se o programa Gap Light Analyser v, 2.0 (FRAZER et al., 1999), para obtenção da porcentagem de abertura de dossel (PAD). Para os dados de composição do entorno em um buffer de $1 \mathrm{~km}$, utilizamos o software ArcMap 10.3, com o cálculo dos polígonos contidos dentro desse buffer que pertencessem aos usos de terra. O maior nível de isolamento seria proporcional ao maior percentual de área no buffer das classes Pastagem, Lavoura temporária e Floresta Secundária em Estágio Inicial (=capoeira). As demais classes indicam cobertura arbórea mais fechada, mesmo quando se tratando de áreas de fruticultura ou cabruca mais aberta. Para determinação das variáveis da paisagem com maior impacto sobre os dados de riqueza, foi feita uma analise exploratória de Componentes Principais (PCA), com isto analises de regressão foram realizadas para estabelecer a relação com variáveis da comunidade. A resposta da comunidade de Scarabaeinae às variáveis abióticas foi analisada através de uma Análise de Variância (ANOVA) fatorial, considerando como variáveis explicativas os fatores estruturais e espaciais dos fragmentos tendo como variáveis respostas a riqueza e a abundância de espécies.

Foi feita a correlação da composição de espécies dos fragmentos com a variável estrutural da vegetação e com as variáveis espaciais de cada fragmento amostrado. Uma matriz de similaridade (métrica de Bray-Curtis) foi analisada por um NMDS (escalonamento multidimensional não métrico) com 30 reinícios. Os agrupamentos apresentados no NMDS com stress menor que 0,20 considerados representativos foram validados por uma Análise de Similaridade de duas vias (two-way ANOSIM) com 50000 permutações.

\section{RESULTADOS E DISCUSSÃO}

As seis áreas escolhidas (Tabela 1, Figura 1) para o desenvolvimento do presente trabalho foram identificadas através dos nomes dos proprietários de terras (parceiros da OCT) através das quais os fragmentos florestais foram acessados.

Tabela 1. Medidas físicas dos fragmentos, percentuais de uso de terras no entorno dos fragmentos (buffer de 1km) e dados quantitativos das comunidades de Scarabaeidae amostrados nos fragmentos na APA do Pratigi. Fragmentos identificados pelos nomes dos proprietários dasterras através das quais os fragmentos foram acessados.

\begin{tabular}{lcccccc}
\hline Proprietário & Adeilton & André & Branco & Coco & Jairo & Waldemar \\
\hline Área $(\mathrm{km})$ & 3,44 & 19,01 & 0,17 & 1,58 & 0,159 & 3,42 \\
Perímetro $(\mathrm{km})$ & 28,42 & 39,68 & 5,26 & 24,04 & 3,63 & 65,5 \\
Índice de Circularidade & 0,004 & 0,012 & 0,0061 & 0,003 & 0,012 & 0,001 \\
Abert. de dossel (média \%) & 29,581 & 22,024 & 30,467 & 22,617 & 21,56 & 26,786 \\
Abert. de dossel (dp \%) & 6,217 & 5,739 & 3,587 & 6,448 & 6,150 & 7,603 \\
Cabruca & 11,165 & 15,591 & 2,070 & 4,466 & 15,678 & 18,117 \\
Floresta - médio ou avançado & 32,182 & 11,616 & 26,126 & 23,186 & 16,510 & 21,555 \\
Floresta - estado inicial & 12,111 & 13,423 & 15,048 & 10,891 & 4,376 & 7,740 \\
Lavouras permanentes & 32,396 & 17,088 & 23,731 & 30,997 & 22,772 & 23,468 \\
Lavouras temporárias & 4,194 & 41,606 & 2,9056 & 9,699 & 8,705 & 24,705 \\
Pastagens & 7,890 & 0,675 & 29,384 & 20,668 & 31,958 & 4,414 \\
Silvicultura & 0,061 & 0 & 0,735 & 0,091 & 0 & 0 \\
\hline Abundância & 983 & 382 & 145 & 168 & 116 & 384 \\
Riqueza & 28 & 12 & 17 & 13 & 11 & 19 \\
Diversidade (H') & 1,743 & 1,080 & 1,534 & 1,516 & 1,444 & 1,562 \\
\hline
\end{tabular}




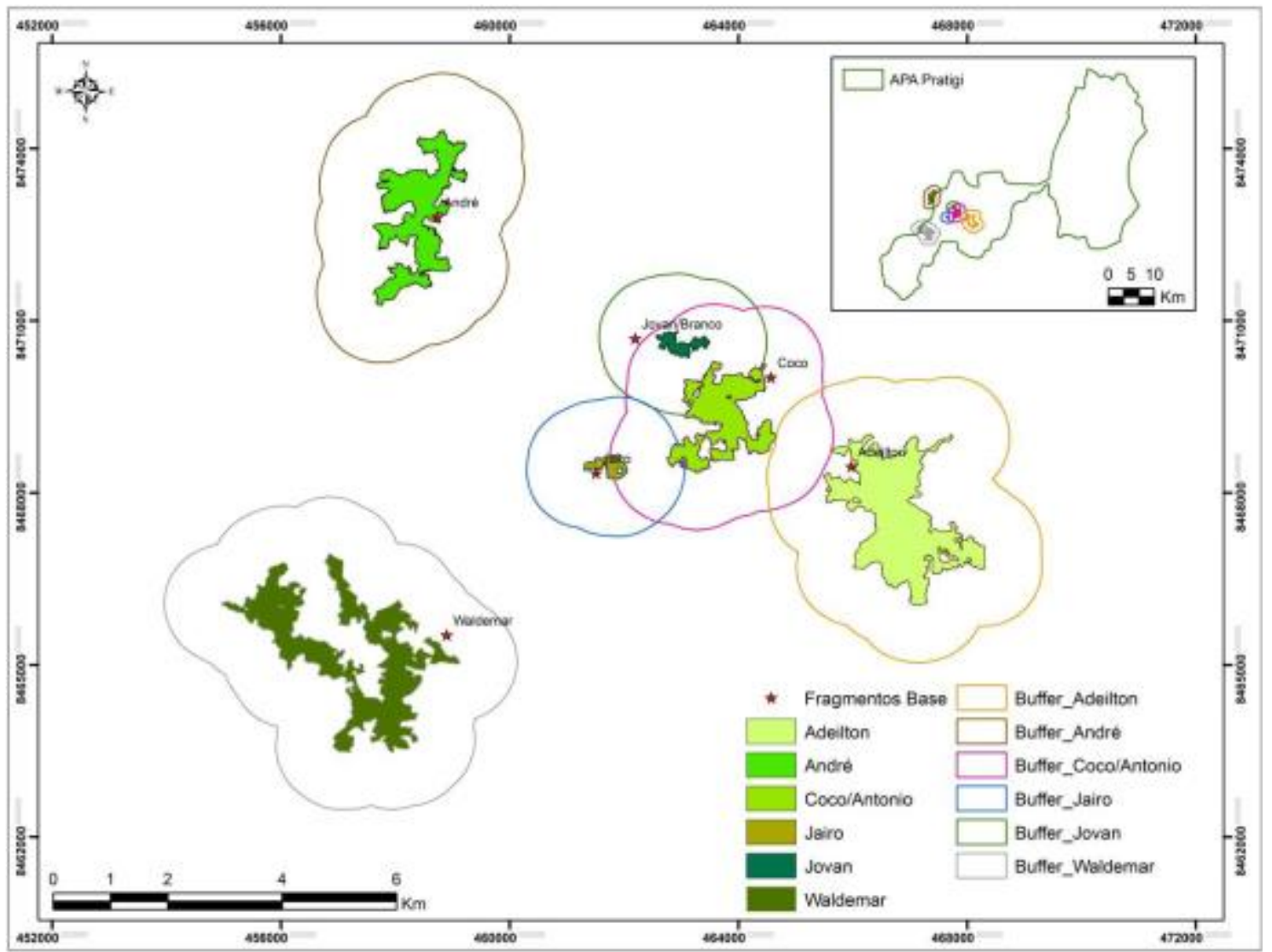

Figura 1: Mapa do Ecopolo I da Apa do Pratigi e localização dos fragmentos florestais amostrados. Estrelas indicam os pontos de entrada nos fragmentos. Linhas externas aos fragmentos correspondem ao buffer de 1 km. Produção do Mapa: Liamara Carelli, 2016.

Os percentuais de cobertura das categorias de uso de terras demonstraram uma predominância de formações mais fechadas (Cabruca, Floresta Primária e Secundária em Estágio Médio ou Avançado, Lavoura Permanente e Silvicultura) nos entornos dos fragmentos $(58,3 \%)$, enquanto que as mais abertas (Floresta Secundária em Estágio Inicial, Lavoura Temporária e Pastagem) se distribuíram por $41,7 \%$ da área do entorno. Em termos das variáveis relacionadas à abertura do dossel, os fragmentos não se distinguem estatisticamente, de forma que não foram consideradas nas análises espaciais.

Foi coletado um total de 1607 indivíduos divididos entre 28 espécies, sendo que nas iscas de fezes humanas obteve-se quase sete vezes mais indivíduos que as iscas de carcaça, sendo o crescimento da abundância em cada isca consistente com o aumento da área. Segundo a literatura, as fezes humanas são mais atrativas, evidenciando mais eficientemente a maior riqueza e abundância de espécies em determinadas áreas, principalmente em matas (HANSKI \& CAMBERFORT, 1991). O uso de carcaça no presente estudo acrescentou à amostragem as espécies necrófagas Canthon nigripennis Lansberge, 1874, Coprophanaeus dardanus Macleay 1819, C. bellicosus (Olivier, 1789), Deltochilum calcaratum Bates, 1870, D. prox. irroratum e Eutrichillum hirsutum Boucomont, 1928.

A correlação entre riqueza, abundância e as variáveis dos fragmentos e variáveis espaciais não evidenciaram claramente nenhum efeito que indicassem a influência de poucas variáveis. A somatória das formações abertas em uma categoria única e as formações fechadas em outra, diferindo do esperado, não foram significativamente 
relacionadas com a diversidade, apesar de aparentarem uma relação negativa e positiva, respectivamente. A regressão de riqueza com a categoria Florestas secundárias em estado médio ou avançado de regeneração também não foi significativa. O esperado se baseia na pressuposição de que se havendo mais áreas florestais em posições mais próximas, o isolamento seria reduzido e a riqueza poderia ser maior (MACARTHUR \& WILSON, 1967). As relações significativas foram estabelecidas entre a riqueza e a área dos fragmentos $(r=0,6772 ; p=0,000)$ e com a abertura do dossel $(r=0,8005 ; p=0,0036)$. Apesar de esperarmos que o medida de desvio padrão do percentual de abertura do dossel fosse positivamente relacionada à diversidade, por indicar heterogeneidade da formação vegetal (TEWS et al. 2004), essa relação não foi significativa. A mesma ausência de significância foi encontrada para a relação entre riqueza e índice de circularidade, em que se esperaria que áreas mais circulares gerassem maior diversidade (SCARIOT et al., 2003). A área mais circular foi uma das menores, e as áreas grandes se mostraram intensamente recortadas, de forma que essa relação direta foi truncada.

As análises das comunidades de Scarabaeidae mostram que as comunidades dos vários fragmentos não são dissimilares (NMDS, Bray-Curtis, stress=0,1341; ANOSIM, p>0.55), com o fragmento mais dissimilar sendo Adeilton, o de maior área, mas ainda assim, não significativamente diferente dos demais. Os fragmentos mais similares entre si são igualmente os mais próximos (Figura 1), mas apesar da proximidade de Adeilton desse grupo de fragmentos, se manteve menos similar.

\section{CONSIDERAÇÕES FINAIS}

De acordo com alguns testes estatísticos comprovou-se a que os fragmentos são todos iguais; onde a diversidade de abundancia e riqueza assim como a similaridade entre ambos não apresentam uma valor significativo, para que seja determinada apenas um ou mais componentes que indiquem variação nos fragmentos. Deste modo as espécies encontradas nos fragmentos comprovam a grande abundancia e riqueza de indivíduos da comunidade Scarabaeinae em fragmentos de mata. Ponderando as variáveis do fragmento e as variáveis espaciais do entorno, as primeiras parecem explicar melhor a variação dos dados bióticos do que as variáveis da paisagem.

\section{REFERÊNCIAS}

FRAZER, G.W.; CANHAM, C.D.; LERTZMAN, K.P. 1999. Gap Light Analyzer (GLA), Version 2.0: Imaging software to extract canopy structure and gap light transmission indices from true-colour fisheye photographs. Simon Fraser University/ Institute of Ecosystem Studies.

HANSKI, I. \& CAMBEFORT, Y. 1991. Dung Beetle Evolution. Princeton University Press.

MACARTHUR, R.H., WILSON, E.O. 1967. The Theory of Island Biogeography. Princeton: Princeton University Press.

METZGER, 2001. O que é Ecologia de Paisagens? Biota Neotropica v1 (n1) BN00701122001

OCT (Organização de Conservação da Terra), 2015. Apresentação da APA do Pratigi. Disponível em http://www.oct.org.br/apa-do-pratigi/Apresentacao/19, acesso 09 Agosto 2016.

SCAIOT, A. et al. Efeitos da fragmentação sobre a biodiversidade Vegetação e flora. In: RAMBALDI, D. M.; OLIVEIRA, D. A. S. (Orgs.). Fragmentação de ecossistemas: causas, efeitos sobre a biodiversidade e recomendações de políticas públicas Brasília: MMA/SBF, 2003. p.103-123.

SCHOOLMEESTERS, P. et al. 2010. ScarabNet Global Taxon Database (version 1.5). http://216.73.243.70/scarabnet/results.htm. 
TEWS, J. et al. . 2004. Animal species diversity driven by habitat heterogeneity /diversity: the importance of keystone structures. J. Biogeogr. 31, 79-92. 